\title{
embajada de U.S.A.
}

E. D. STONE, arquitecto

La embajada de los EE. UU. en la India, recientemente terminada, sigue las directrices de la nueva arquitectura en el país. Inspirada en los monumentos clásicos-el famoso Taj Mahal, mausoleo construído en mármol blanco-, el edificio de la embajada es único por su prodigiosa adaptación a los estilos arquitectónicos históricos, manejando los más modernos métodos y materiales de construcción.

Asentada sobre un amplio solar-jardín, en el barrio diplomático de Nueva Delhi, el complejo constructivo consta de: Cancillería, zona residencial y viviendas de empleados.

\section{Edificio principal}

El edificio de la Cancillería es rectangular en planta, con lados de 58 y $122 \mathrm{~m}$, y se levanta sobre un plinto de $2,10 \mathrm{~m}$ de altura. Se compone de dos plantas elevadas, con aire acondicionado, y un sótano. Este último aloja todas las instalaciones, tales como aire acondicionado, purificación de aguas, teléfono, subestación eléctrica, almacén indio, etc.; además están previstos dos espacios de aparcamiento para 50 coches cada uno, en la parte delantera y trasera, y de aquí arranca el ascensor que conduce a las plantas superiores.

La biblioteca, sala de conferencias y oficinas públicas están ubicadas en la planta baja, reservándose el piso superior para el despacho del embajador y otras oficinas más nobles. 


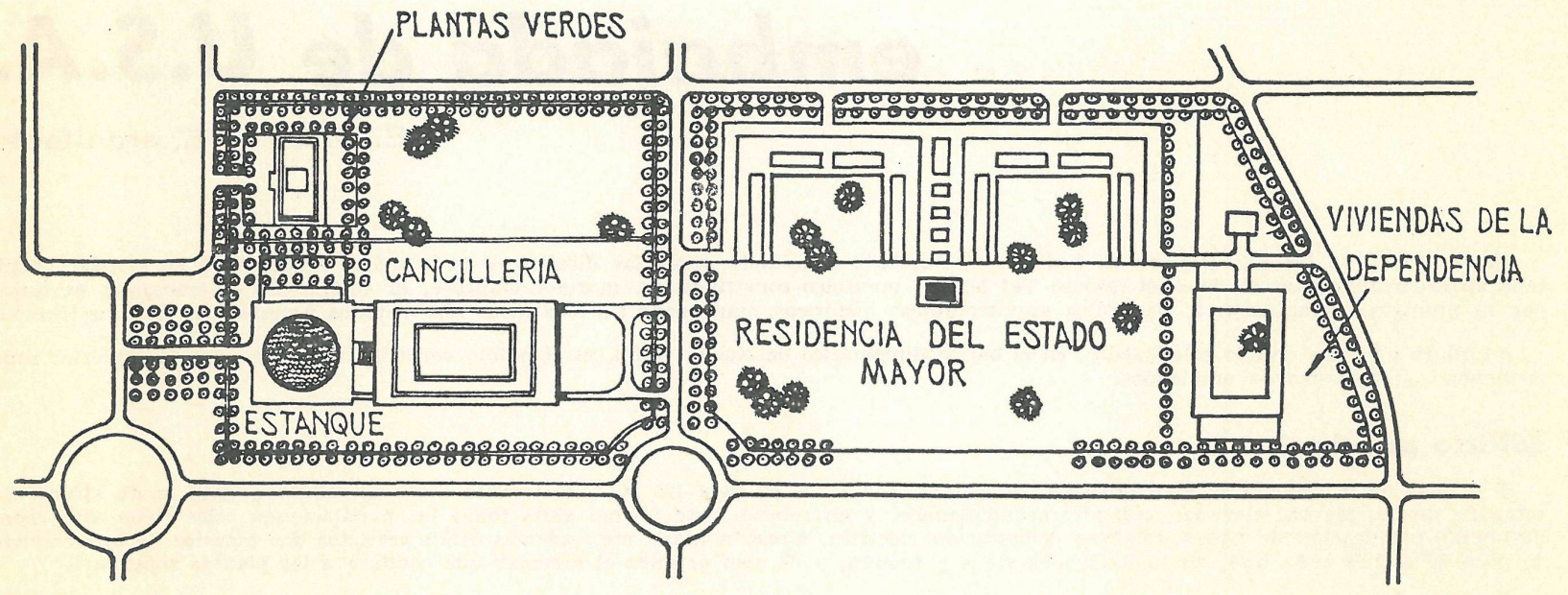

situación 

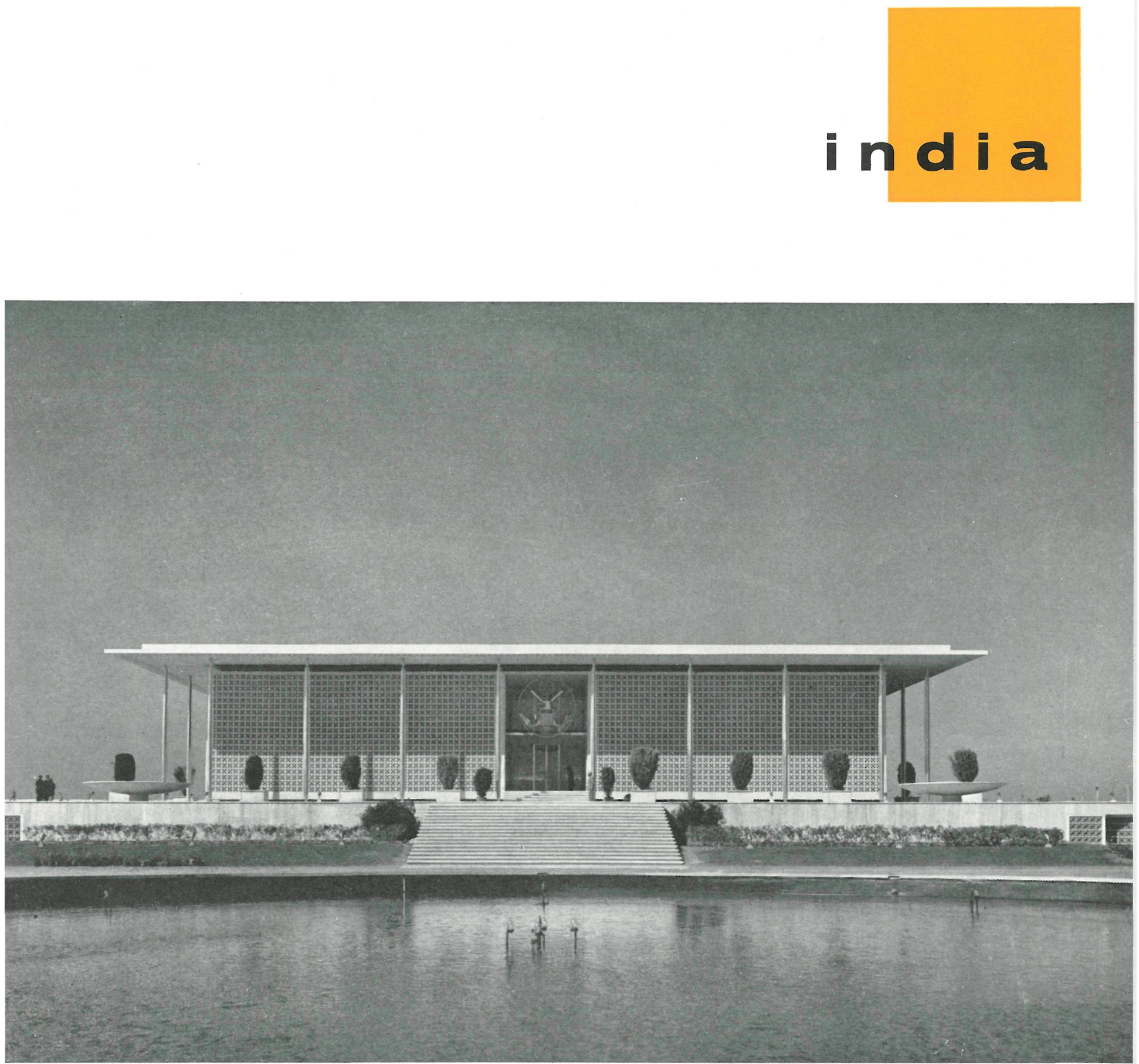

El patio interior, entre ambas plantas altas, alberga un jardín acuático, al que procura sombra una artística celosía de aluminio. Todas las oficinas están situadas bordeando dicho jardín con la sala de conferencias al fondo, la cual va provista de grandes puertas correderas de cristal que permiten la vista maravillosa de los juegos de luz y sombra, proporcionados por el techo enrejado de aluminio sobre el jardín.

\section{Arquitectura}

$\mathrm{Su}$ arquitecto, E. D. Stone, inspirado en la rica herencia de los estilos locales, ha creado un proyecto agradable, sereno, armonioso y fuertemente original, con un concepto abierto y despejado.

La totalidad del edificio está construída sobre una plataforma o podium elevado, similar al del Taj Mahal, pavimentada con mármol blanco incrustado con piedrecillas del Ganges. Rodeando todo el edificio y en toda la altura de las dos plantas superiores, una celosía de terrazo blanco forma como un muro calado exterior. Algo separados de estos muros reticulados, una hilera de pilares, revestidos con finas hojas de oro, soportan el fuerte volado de la cubierta. Una amplia escalera con grandes peldarios volados de mármol, de unos 11 m, asciende hasta la parte superior del podium basal. 


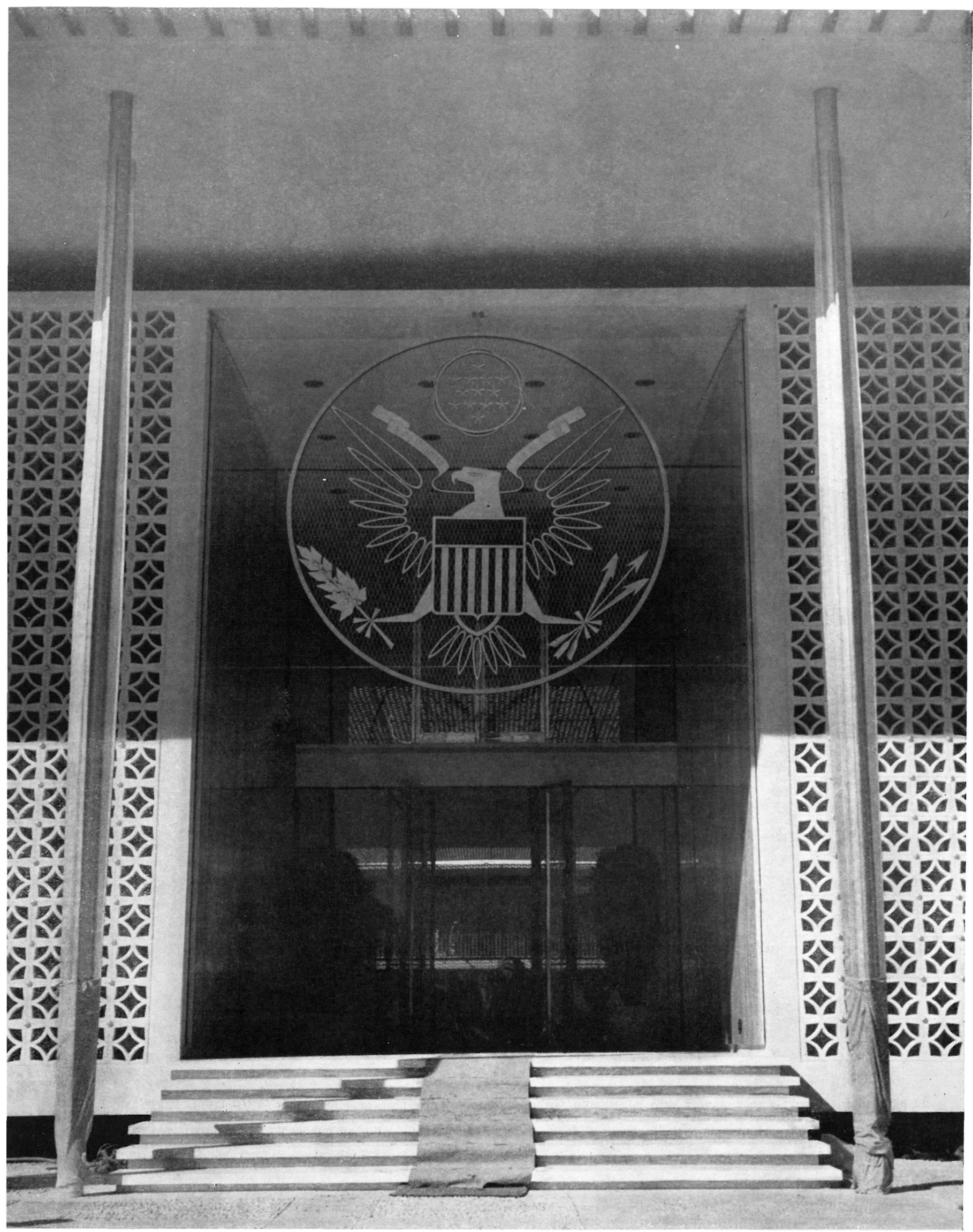

portada 


\section{celosia}

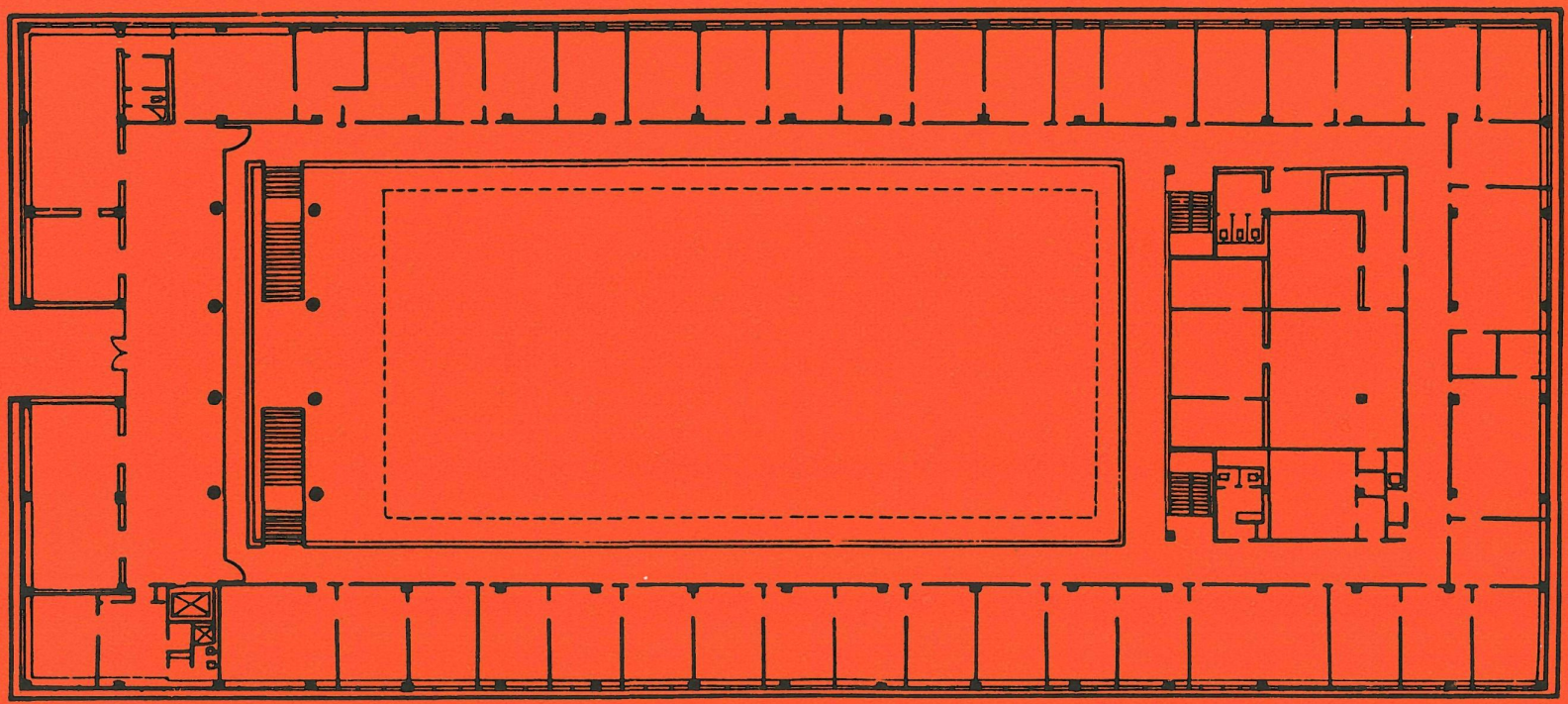

Pilares

$$
\begin{aligned}
& \text { PILARES } \\
& \text { DOORADOS }
\end{aligned}
$$

CELOSIA

/ PLANTAS

OORAOCS

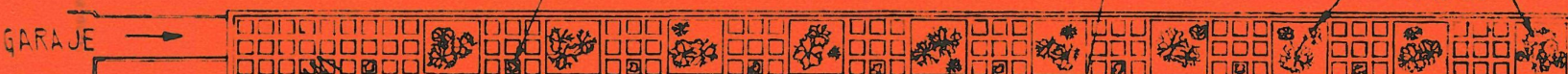

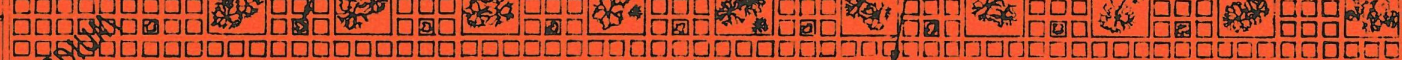
ost

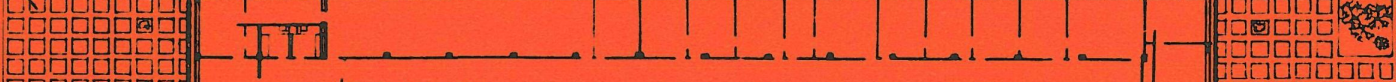

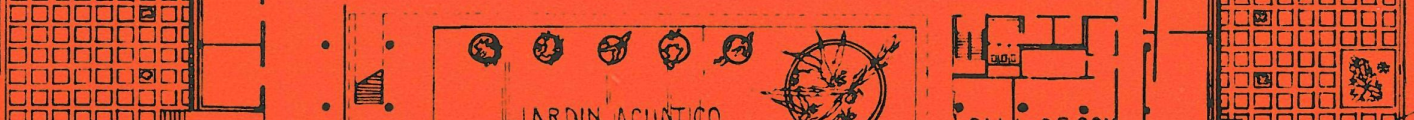
4 - NARDIN ACUATICO (a) - PRINCIPAL | a

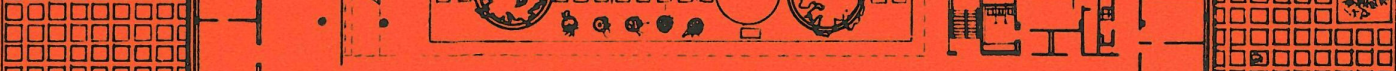

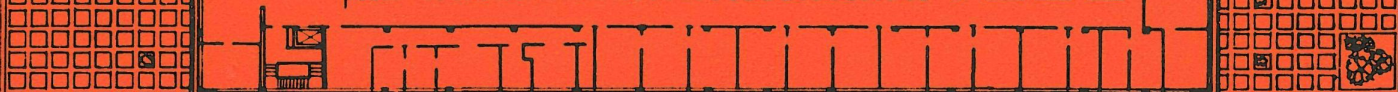

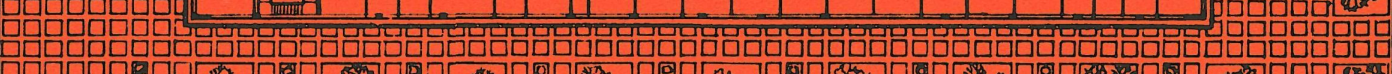

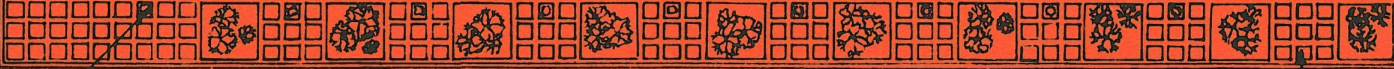
GARAJE $\longrightarrow$

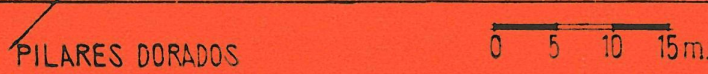

LOSAS INCRUSTADAS CON GUIJOS DEL GANGES

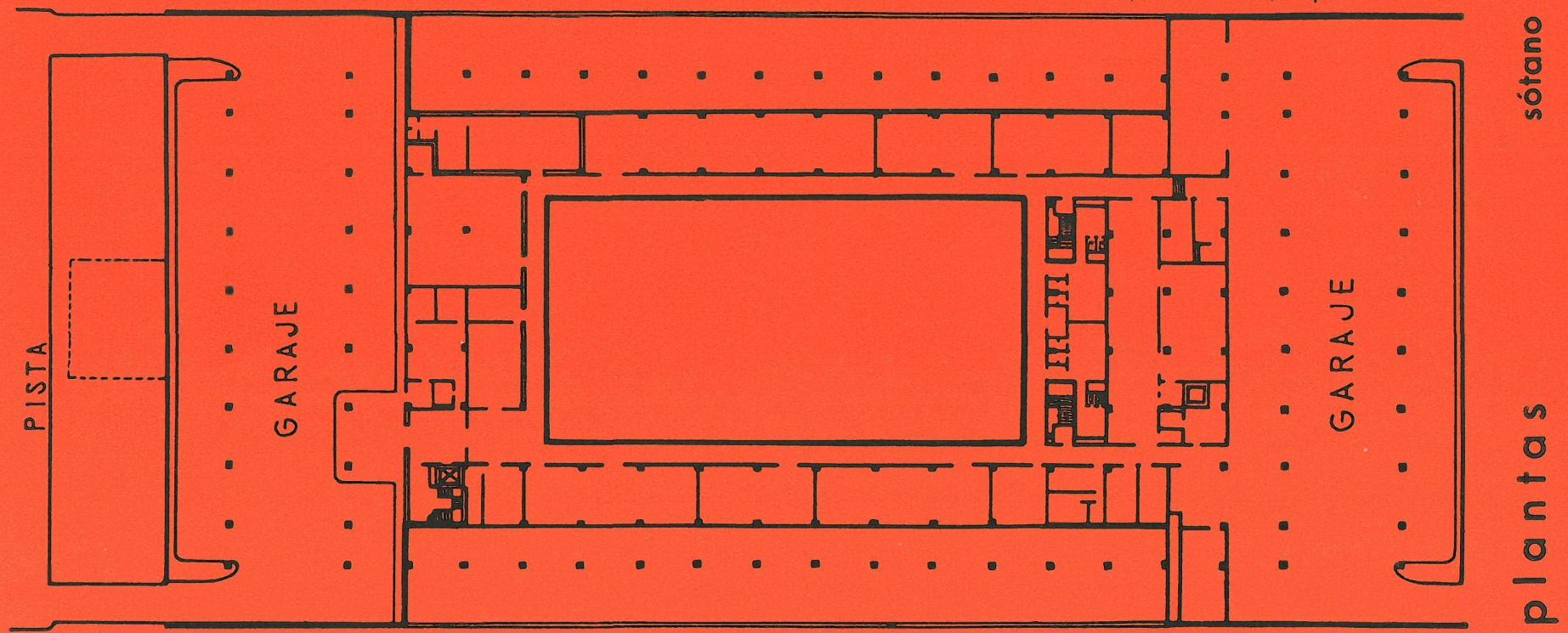




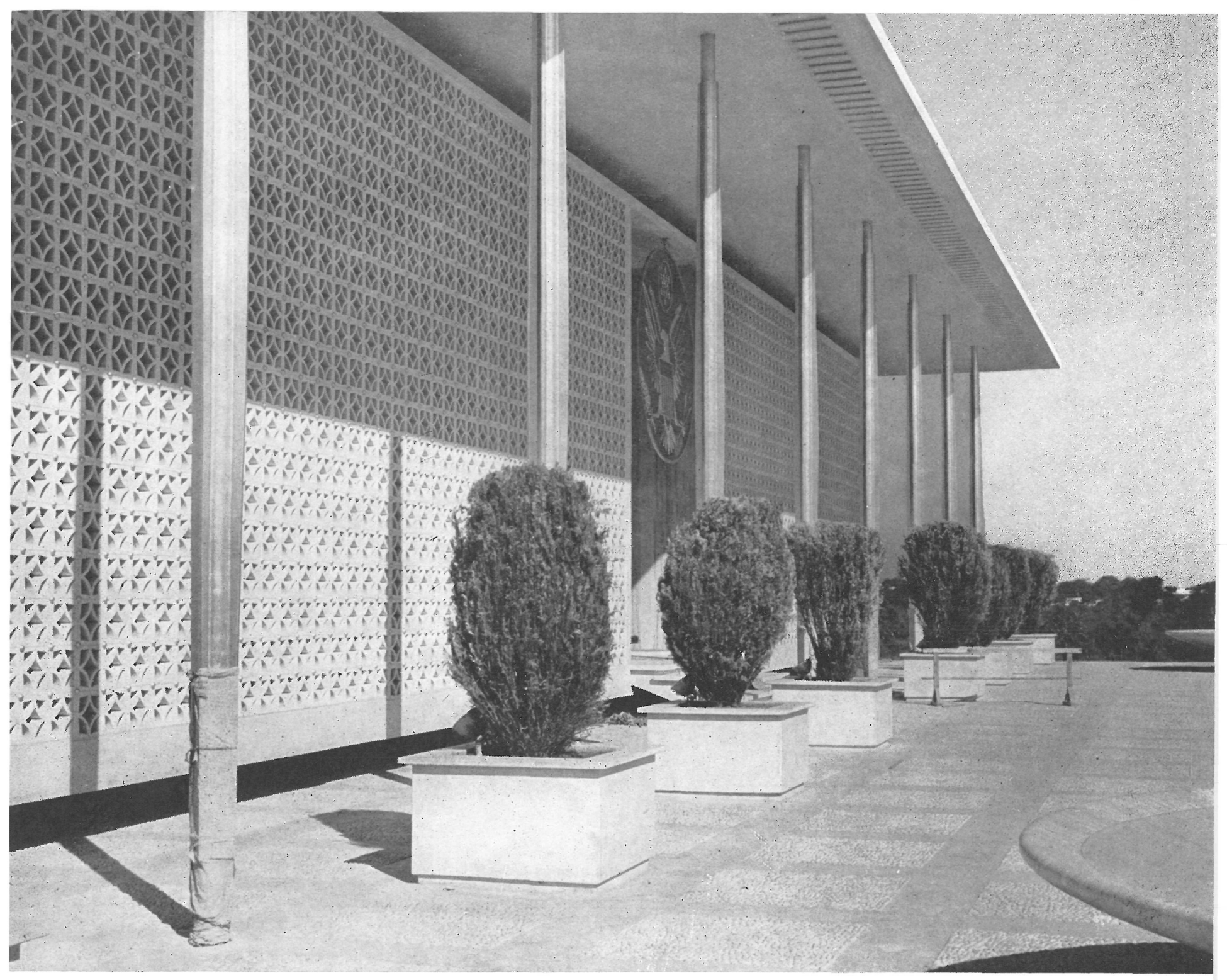

En la fachada principal de la Cancillería-que corresponde a un lado menor del rectángulo-, al final de la escalinata, se abre una espaciosa puerta de cristal, protegida en su parte exterior por una pesada reja de bronce. Sobre ella, y colgando del techo, campea un gran escudo dorado. El vestíbulo está "cerrado» por una blanca reja metálica, dispuesta así para proporcionar una libre vista hacia el jardín acuático.

Las características fundamentales arquitectónicas del edificio están representadas por el blanco enrejado exterior de terrazo, oficinas, terrazas, columnas docitios, techos volados, el podium antedicho, jardín, estanque-espejo y la extrema sencillez de todo adorno y mobiliario interior. Las habitaciones están tratadas acústicamente, en su totalidad, con placas de piso de terrazo, con tres de sus muros pintados de blanco ostra, y el cuarto, de cristal plano, protegido por un enrejado exterior de terrazo. Los falsos techos son de madera pintados de blanco ostra, y el cuarto, de cristal plano, protegido por un enrejado exterior de terrazo. Los falsos techos son de madera
pintada de blanco y van provistos de un dispositivo especial, reticulado, capaz de proporcionar luz uniforme, suprimiendo las sombras molestas. Todo el encanto estético del edificio se refleja brillantemente en el gran estanque circular, de $43 \mathrm{~m}$ de diámetro, situado frente a la Cancillería y a la otra parte de la pista de acceso.

\section{Sistema estructural}

La placa de cubierta, así como las columnas y vigas, son de hormigón armado; los muros divisorios, de bloques huecos de hormigón; los muros del sótano, de hormigón armado y de $30 \mathrm{~cm}$ de espesor. Los forjados, de placas huecas armadas, con nervios de $36 \mathrm{~cm}$, aprovechándose estos huecos rura instalar los conductos principales de electricidad y teléfono.

El enrejado decorativo exterior es de hormigón y piezas prefabricadas de terrazo, como ya indicamos anteriormente. Las columnas, cubiertas con finas hojas de oro, son de un gracioso perfil, ancho en el centro y con disminución hacia ambos extremos.

El acabado del piso y de todos los muros exteriores que miran hacia el jardín acuático es de terrazo blanco en losas o fabricado «in situn; este último forma cuadros, separados por juntas brillantes de bronce. 

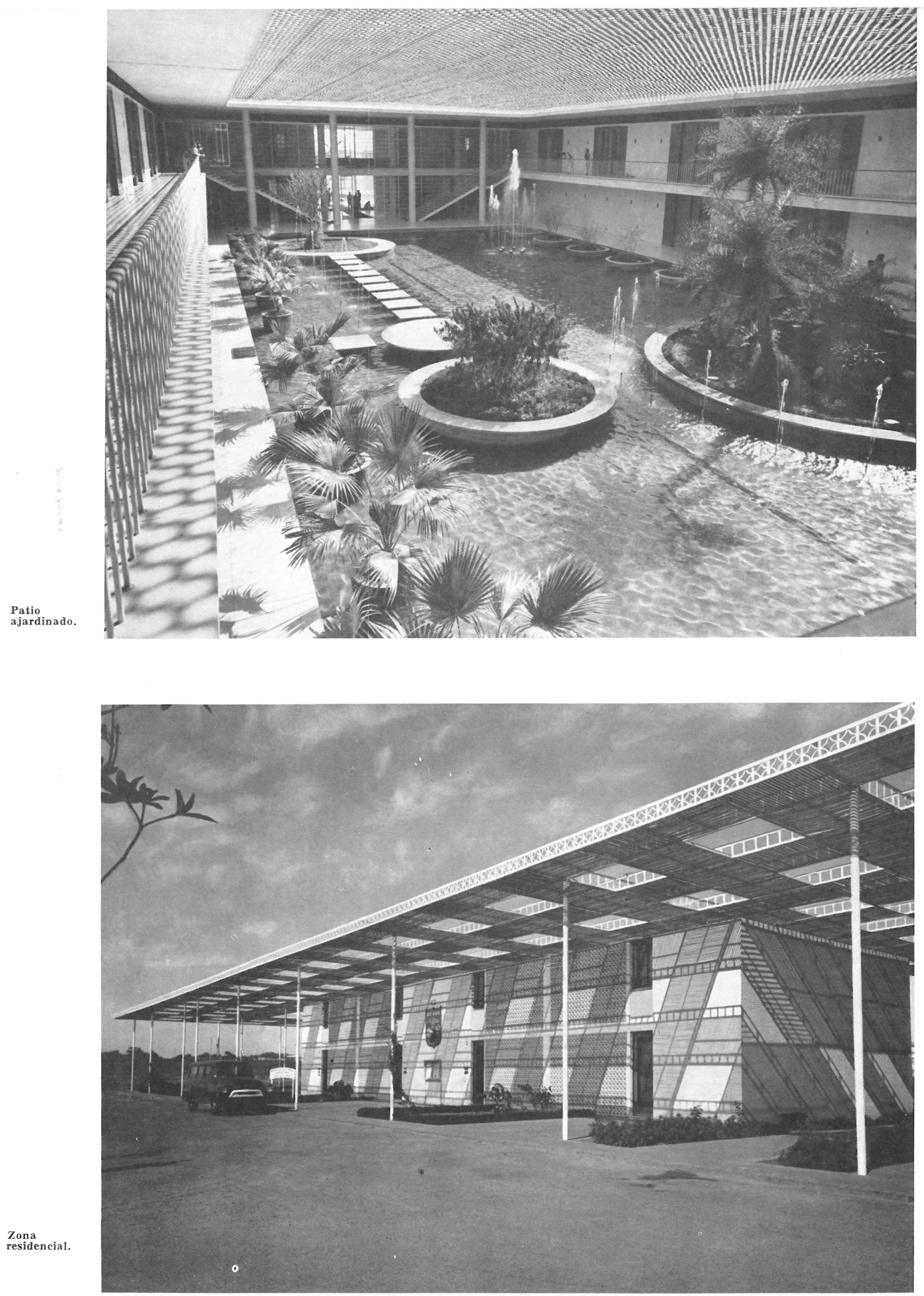


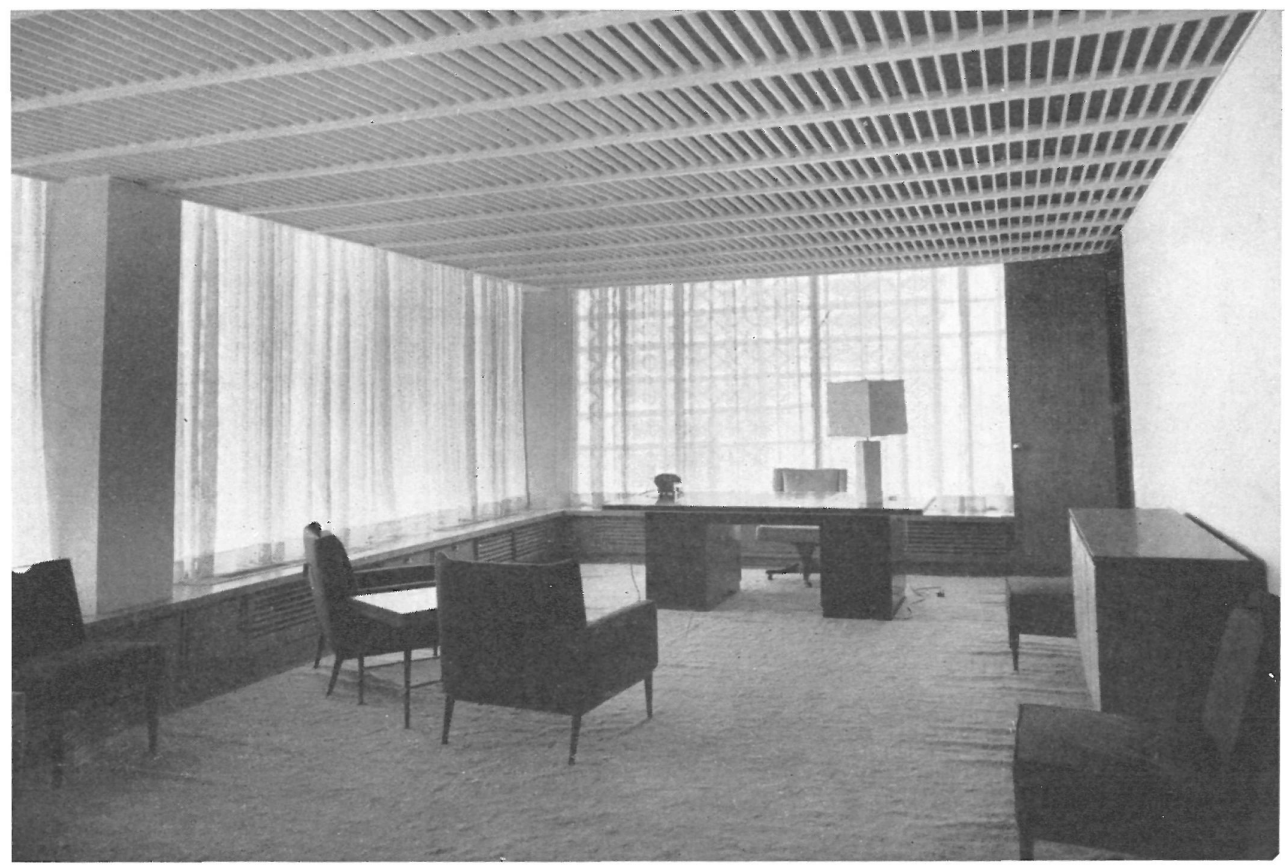

interiores

Los sistemas de aislamiento contra el calor proporcionados por el hormigón aireado, los enrejados, la celosía del techo del jardín... tienden todos ellos a disminuir gastos excesivos de aire acondicionado y aminorar deslumbramientos. Hay juntas de dilatación de cobre y metales deslizantes en columnas, vigas y placas, así como a lo largo de todo el edificio.

Tanto el sótano como los estanques están impermeabilizados con gunita, forros bituminosos y láminas de alkathene.

\section{Conclusión}

El arquitecto de esta magnífica obra, al ejecutar tan notable proyecto-original y, a la vez, de fisonomía familia en el paisaje indostánico-, añade nuevos valores a la arquitectura y a los estilos artísticos históricos del país.

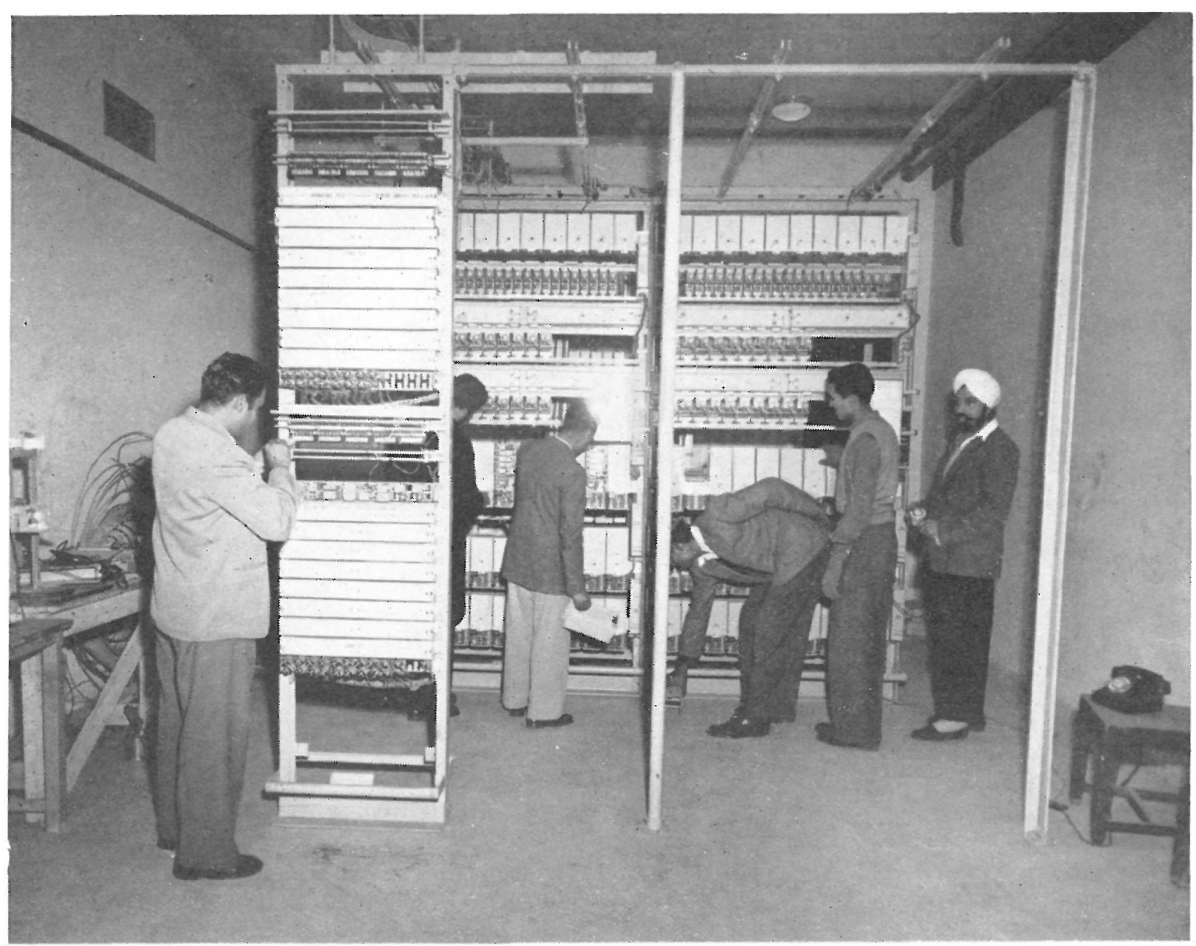

